\title{
Por uma Visão Estratégica dos Instrumentos Urbanísticos - Questão de Limiares
}

\author{
Rosa Maria Puchala
}

Resumo

A prática de planejamento urbano no Brasil dispõe de alguns instrumentos de intervenção urbana de pouca eficácia diante dos múltiplos fatores interativos que atuam na dinâmica urbana. Os instrumentos jurídicos e institucionais disponíveis derivam da Constituição, a qual define as relaçōes entre os agentes, Estado e sociedade, que exercem a intervenção urbana.

Os instrumentos constitucionais devem ser revistos no sentido de superar as limitações do poder público no trato de bem comum ou interesse da sociedade, fator de racionalidade coletiva fundamental para a intervenção no desenvolvimento urbano.

\begin{abstract}
Urban planning practice in Brazil disposes only of a few urban intervention instruments. But, these are not efficacious or powerful to attack the multiples factores that produce urban development. Juridical and institucional instruments derive from Constitution, which defines relationships between agents, State and society, and also between levels of Public Power which make togheter urban interventions.

Constitucional instruments need to be reviewed to surpass their limits, introducing changes in State-society relationship, and also promoting a comprehensive treatment of urban dynamics.
\end{abstract}




\section{Introdução}

O presente documento ensaia uma visão estratégica dos Instrumentos de Intervenção Urbanística (I.I.U.). Significa dizer que busca indicar os fatores limitativos, ou "contra" sua aplicação eficaz, tendo em vista abrir a reflexão para novos Instrumentos Urbanísticos (I.U.) mais coerentes com as necessidades de intervenção no fato urbano nacional.

Os principais fatores limitativos referem-se às questões de sustentação dos (I.U.) pela Política Urbana (P.U.) em nível nacional, pelo exercício do planejamento, no trato do desenvolvimento urbano, e pela relação Estado-sociedade.

O requisito constitucional (art. 182 - Constituição Federal/88) de vinculação da P.U. ao Plano Diretor (P.D.) pode ser interpretado como um indício de sensibilização às questões de sustentação dos I.U.. Pesam, porém, contra o P.D., na condição de instrumento legal, as limitaçōes do poder público municipal - (P.P.M.) e a inércia setorial e de curto prazo do planejamento municipal.

A definição da P.U. pelo P.P.M. é um equívoco constitucional. As relações de autonomia e dependência municipal, tanto no âmbito jurídico como do desenvolvimento urbano, destinam aos I.U. uma função irrelevante frente à P.U.. Em contrapartida, submetem os $1 . U$. aos riscos dos interesses conjunturais de políticas isoladas e oportunistas.

As questōes de doutrina do Estado caracterizam outro conjunto de fatores, não propriamente limitativos, mas impeditivos da formulação de I.U. coerentes com as novas formas de inserção do Poder Público (P.P.) na sociedade.

É assim que a Constituição Federal (C.F./88) reproduz uma ótica de Estado regulador do interesse social e provedor de bens e serviços, sob a forma de restriçōes e ônus ao particular.

Esta ótica responde a uma realidade urbana precedente a C.F./88, correspondente ao período do chamado Milagre Brasileiro, décadas de 60 e 70 , quando a intervenção do P.P na questão da terra urbana representava uma bandeira social para atenuar os efeitos de uma economia perversa. Faltou a C.F./88 a ótica das transformaçōes sociais, políticas e econômicas, que já se gestavam na década de 80 , e que sucessivamente, vêm induzindo à reformulação do papel do Estado e da intervenção do P.P. na sociedade. Na prática, surgem as parcerias entre P.P. e setor privado e uma maior capacidade de influência da sociedade civil organizada.

Dada a defasagem entre o fato legal e a prática social, surge a necessidade de aperfeiçoamento, e mesmo de criação, de instrumentos de participação, para articulação e gerenciamento aos fatores do desenvolvimento urbano.

Estes instrumentos se identificam com recursos de gestão urbana que, uma vez aperfeiçoados podem propiciar mudanças nos aspectos de doutrina do Estado e resultar em maior equilíbrio nas relações do P.P. com o capital e a sociedade. É sob o princípio de gestão que podem ser instituídos novos I.U. mais eficazes.

A história da urbanização recente vem confirmando estas transformaçōes. É o que sucede, particularmente, nas áreas de grande crescimento urbano e concentração de capital.

$\mathrm{Na}$ Cidade de São Paulo, a Prefeitura Municipal vem ensaiando, após a abertura democrática de 1983, novas atribuiçōes de gestão, sob a forma de I.U. baseados 
no princípio da parceria, em particular com o empresariado detentor do capital para investimento.

Tais instrumentos de política urbana não estão abrigados constitucionalmente, mas representam uma ótica real em contraposição à ótica legal.

\section{Sobre a Aplicação dos Instrumentos Urbanísticos Vigentes}

\section{Questões de Doutrina}

\section{Os Instrumentos Urbanísticos Constitucionalmente são de Competência Municipal}

As disposições constitucionais referentes aos I.U. atribuem o exercício da P.U. ao P.P.M. De acordo com art. 182 da C.F./88, "cabe ao P.P.M. executar, através do P.D., a política de desenvolvimento urbano, que tem por objetivos ordenar o pleno desenvolvimento das funções sociais da cidade e garantir o bem-estar de seus habitantes"

OP.D. é instituído como instrumento legal da "política de desenvolvimento e de expansão urbana" e de "definição da função social da propriedade urbana"

\section{Abrangência Espacial do Desenvolvimento}

Controvérsias no tocante à abrangência espacial do P.D, decorrem do texto constitucional. Seguido o disposto na C.F./88, o P.D. se restringe à área urbana. Nestes termos, gera-se um impasse quanto à abrangência espacial do desenvolvimento urbano, flagrado pela Constituição do Estado de São Paulo C.E./89, no art. 181.

\section{Natureza dos Instrumentos Urbanísticos}

De acordo com a C.F./88, os I.U. são os meios operacionais da P.U. e do P.D.. São instrumentos de natureza jurídica, tributária e financeira - IPTU progressivo, desapropriação, parcelamento ou edificação compulsórios, usucapião urbano.

Apesar de suas finalidades diversas quanto à intervenção na terra urbana, os I.U. possuem em comum o princípio da garantia e salvaguarda, pelo P.P., da função social da propriedade urbana, na forma de ônus à propriedade privada e ao capital. Em contrapartida, sua aplicação pode reverter favoravelmente para o P.P.M., na forma de arrecadação de impostos ou da incorporação ao domínio público de áreas privadas.

O Intervencionismo de Estado Implícito na Formulação dos Instrumentos Urbanísticos

Nesta formulação dos 1.U. está implícito o conflito do papel do P.P. em uma sociedade capitalista, onde a propriedade é a gênese. O princípio de P.P. regulador da função social da propriedade, através do gerenciamento do estoque e da rentabilidade da terra urbana, permeou todo o pensamento político que gestou a transição democrática após a falência do modelo de desenvolvimento econômico do milagre brasileiro: 
Historicamente, é justificável a defesa do interesse social, como fator estrutural do intervencionismo do Estado. Após a década de 80 , porém, as questões de natureza social-urbana não podem ser reduzidas à posse e renda da terra, nem tampouco, se limitar à intervenção autoritária do Estado.

Cumpre organizar plataformas políticas que possibilitem o exercício do direito à cidade, bem como ao desenvolvimento urbano, pela sociedade como um todo. A ação do P.P. deverá se ajustar às novas condições de intervenção de acordo com a tomada de decisões política e socialmente compartilhadas.

\section{Limitaçðes do Poder Municipal}

\section{Natureza do Poder Municipal}

Com a C.F./88, o município atinge a condição de ente federativo. De acordo com art. 29, é outorgada ao Município a Lei Orgânica Municipal - L.O.M., o que corresponde a uma carta constitucional. Outros dispositivos constitucionais estabelecem as competências municipais, seja no âmbito do interesse local e de suplementação legal às competências da União e dos Estados, seja no âmbito do sistema tributário nacional (art. 156 a 162).

Estes dispositivos representam reformas no papel do Estado, no sentido da redução da dependência do P.P.M. aos demais níveis do poder federal e estadual. A nova entidade federativa se impõe como princípio de descentralização do Estado, levado a termo pelo municipalismo.

Ao contrário do princípio de união, inerente ao conceito de federação, a nova inserção do poder municipal surge como divisão entre os poderes constituídos em um momento de revisão do centralismo e autoritarismo de Estado, que corresponde, aproximadamente, à década de 80 .

\section{Autonomia e Dependência Municipal}

A atribuição da P.U. ao P.P.M. é coerente com os princípios de autonomia municipal que embasam a carta constitucional. Resulta, porém, um federalismo municipalista não suficientemente equacionado quanto aos aspectos de concentração de poder da União e dos Estados, o que se manifesta nas formas de dependência do P.P.M. aos demais níveis de poder.

É na dualidade autonomia-dependência do P.P.M. que se situam as limitações estruturais de aplicação dos I.U., restritos às questões sociais relativas à propriedade urbana, e que pouca ingerência possuem nas relaçōes do desenvolvimento dependente.

\section{Adequação Constitucional dos Instrumentos Urbanísticos}

As relações de dependência municipal, enquanto fato jurídico, solicitam revisão constitucional, de modo a permitirem a formulação de I.U. que atendam a natureza interativa do desenvolvimento urbano, em sua abrangência nacional e regional.

Tais instrumentos urbanísticos não se limitam ao âmbito do poder municipal. Remetem também ao poder da União e dos Estados e devem ser pensados fora da ótica intervencionista, autoritarista e centralista do Estado. 
$O$ instrumento do planejamento urbano e regional, na condição de instrumento clássico do P.P deve ser repensado de forma vinculada à gestão, de modo a permitir a articulação do P.P., entre seus diferentes níveis e destes com a sociedade e suas forças políticas organizadas.

\section{Limitações do Plano Diretor}

\section{P.D. - Instrumento Urbanístico Constitucional por Excelência}

A C.F./88 vincula os I.U. à P.U. e ao P.D., este na condição de instrumento legal básico da política de desenvolvimento e de expansão urbana, e de definição da função social da propriedade urbana (art. 182).

Ocorre que o P.D. é um instrumento legal frágil diante da falta de vinculação tanto com os meios operacionais do planejamento municipal como com recursos de gestão e participação. Entende-se por meios operacionais a organização política e adminis trativa; o gerenciamento de planos, projetos e programas; a distribuição e aprovação de recursos financeiros, tributários e orçamentários; a integração do executivo ao legislativo e à participação da sociedade.

\section{P.D. - Planejamento e Gestão da Política Urbana}

A falta de vinculação do P.D. com os meios operacionais resulta em prejuízo para - planejamento e a gestão urbana, tendendo a reverter em estratégias governamentais de curto prazo. Resulta que o P.D. é identificado, erroneamente, com programas de governo e associado a finalidades pragmáticas derivadas de políticas conjunturais.

Na prática, O P.D. torna-se um instrumento urbano de retórica, diante da realidade da administração pública municipal. Consequentemente, fica comprometida, na base, a aplicação dos I.U..

\section{Questões de Planejamento e Gestão ficam a descoberto do P.D.}

Questões de planejamento e mesmo da gestão são tratadas emalguns dispositivos constitucionais, independentemente do P.D., e sem interação entre si. Pesa, ainda, a falta de regulamentação, destes dispositivos, pela legislação complementar e ordinária.

Isto ocorre, em particular, no âmbito das disposições sobre a L.O.M. (art. 29), que trata da organização das funções legislativas e fiscalizadoras e da iniciativa popular.

Outros dispositivos de planejamento e gestão ocorrem no título "Da Ordem Econômica e Financeira" da C.F./88, art. 170, que trata das relações entre P.P e setor privado, entre função social da propriedade e propriedade privada, entre defesa de interesses públicos e livre concorrência.

Ocorrem, ainda, nas disposições constitucionais relativas à tributação e ao orçamento, porém sem a devida vinculação entre P.D., plano plurianual, diretrizes orçamentárias e orçamentos anuais (art. 145 a art. 165 da C.F./88). 


\section{A Natureza Regional do Desenvolvimento}

A dependência do desenvolvimento urbano local aos fatores regionais requer instrumentos urbanísticos que afetem os fatores de interação entre cada um dos níveis de poder. É onde se situa o âmbito regional, atribuído pela C.F./88 a Estados, este como instância de interação entre o município e a União.

\section{O Papel Mediador do Poder Estadual quanto à Política Urbana}

A Constituição do Estado de São Paulo - C.E.S.P./89 trata do "desenvolvimento urbano" dentro da "Ordem Econômica" (Título Vl).

Ao poder Estadual cabe suplementar a competência da União no tocante à organização regional (art. 25), cabendo à União o papel de agente normativo e regulador da atividade econômica (C.F./88, art. 74).

No tocante à organização regional, o art. 180 da C.E.S.P./89 dispõe sobre as atribuições do P.P.M. De acordo com este dispositivo, "no estabelecimento de diretrizes e normas relativas ao desenvolvimento urbano, o Estado e o município assegurarão o pleno desenvolvimento das funções sociais da cidade e a participação das respectivas entidades comunitárias... "Outros dispositivos vinculam ainda, o município ao Estado, no caso de se situar em regiões instituídas por este.

\section{A Instância Regional Face à Política Urbana}

$\mathrm{Na}$ prática do desenvolvimento regional a natureza interativa da instância regional dificulta a definição de instrumentos urbanísticos. Isto se agrava pela ingerência dos fatores constitucionais de autonomia municipal, que tendem à desagregação regional através da pulverização de interesses locais.

Também no âmbito do P.P.E., a natureza interativa de intervenção fica prejudicada pela estrutura setorial das atribuições estaduais, dividida em políticas setoriais segregadas e sem a necessária racionalidade global, territorial e espacial.

\section{A Natureza Restritiva dos Instrumentos Urbanísticos}

Os I.U. que predominam, nestas circunstâncias, são a legislação, tanto municipal, como estadual e federal, cuja natureza é restritiva, além de onerar o aparelho administrativo ao qual cabe a sua aplicação. Via de regra, o planejamento regional se reduz ao estreito cumprimento das leis, que por sua vez, são de caráter mais setorial que global. Quando de caráter global, costuma ser precária em regulamentação, em vinculação de procedimentos específicos e em práticas de atualização e monitoramento, próprias de gestão.

Ocasionalmente o caráter restritivo da legislação é atenuado, dependendo de pressões da sociedade organizada.

O aperfeiçoamento dos instrumentos de planejamento e gestão regional poderiam representar recursos estratégicos de superação das limitações constitucionais e dos instrumentos legais disponíveis. 


\title{
Instrumentos Urbanísticos Estratégicos - Questão de Limiares
}

\author{
Os Limiares da Política Urbana \\ O Conceito em Prática
}

As limitaçōes dos I.U. caracterizam questōes de limiares entre os fatores que jogam na política urbana.

A noção de limiar remete à idéia dual de limite e de transição. De limite, na medida em que expressa a idéia de finitude e esgotamento de um determinado sistema. De transição, pois o processo de esgotamento desencadeia a passagem para outros sistemas.

A percepção dos limiares da política urbana pode ser bem útil a uma intervenção estratégica, considerada a natureza interativa dos sistemas de fatores que jogam no fato urbano.

\section{Instrumentos Urbanísticos Estratégicos}

Através concepção estratégica da intervenção no desenvolvimento urbano poderão ser concebidos I.U. que se apliquem aos pontos fracos da política urbana. Estes se situam, principalmente, nos limiares entre os sistemas de fatores que produzem e intervêm no fator urbano e devem ser fortalecidos de modo a favorecerem a transição e a interação entre os sistemas isolados de fatores.

De acordo com as limitações consideradas dos I.U. oficiais, resultam, em termos exploratórios e preliminares, os seguintes limiares básicos:

- Entre os interesses público e privado. Este limiar remete, em decorrência, aos limiares entre interesses ditos sociais e da sociedade propriamente dita; papel do P.P e participação da sociedade; mercado e dirigismo; democracia e autoritarismo;

- Entre competências e atribuições dos níveis do P.P., entre si, e em si. Este limiar não está livre da ingerência dos demais limiares considerados.

- Entre o fato urbano de âmbito local e o desenvolvimento urbano de caráter global. Este limiar remete, em decorrência, aos limiares entre: território e espaço de desenvolvimento; autonomia e dependência; centralismo e descentralização; emancipação e integração.

\section{Gestão Urbana - Instrumento Estratégico}

\section{Gestão - Instrumento de Gerenciamento dos Limiares}

Os instrumentos de gestão urbana são de natureza gerencial. Gerenciar a política urbana implica em inter-relacionar, articular, coordenar os sistemas de fatores que produzem e intervêm na urbanização. Neste sentido, o instrumento de gestão é estratégico, pois recai na necessidade de considerar os limiares onde se travam os processos de interação e onde se situam os obstáculos de gerenciamento. 
Promover instrumentos de gestão, implica em fortalecer os meios operacionais da política urbana, entre outros, o planejamento e a participação social.

Alguns instrumentos de gestão vêm se inserindo crescentemente na prática do planejamento municipal e estadual, como comprovação da coexistência dos instrumentos oficiais com os oficiosos. Esta tendência é justificável com o colapso do P.P. Este se vê diante do impasse em exercer suas competências constitucionais e legais sem desfrutar dos meios efetivos de intervenção.

É o que se manifesta na forma de privatizações, parcerias e compensações que surgem da negociação entre P.P e segmentos sociais. São situações que, na prática, questionam a doutrina autoritária e intervencionista do P.P..

\section{Estudos de Caso}

\section{Gestão de Iniciativa Estadual e Federal}

Contam como iniciativas do Estado de São Paulo, a instituição de instrumentos e foros de gestão, dentre estes:

GRAPROHAB - Grupo de Análise e Aprovação de Projetos Habitacionais, que submete à aprovação de parcelamentos e projetos habitacionais a um balcão único, de modo a articular, não só a administração do Estado, mas também os interessados, entre mutuários e empresários;

Comissão de Gestão dos Recursos Hídricos do E.S.P., que visa gerenciar o uso múltiplo dos recursos hídricos, tendo em vista equilibrar os interesses setoriais do P.P., empresariais e da população, de acordo com uma perspectiva de desenvolvimento sustentado, portanto, não só restritiva;

Projeto Tietê, que visa despoluir o rio Tietê através da ação articulada do P.P.E. com investimentos externos, com o empresariado envolvido, com os municípios, com a sociedade civil organizada e com a sensibilização social;

Fórum Paulista de Desenvolvimento, que visa compartilhar interesses entre P.P.E. e setor privado, com a contrapartida de recursos privados em projetos de interesse público;

Privatização Viária, que visa superar problemas de recursos para investimentos públicos, mediante concessões ao setor privado e em contrapartidas em melhoria e construções viárias, necessária à economia de mercado;

Código de Defesa do Consumidor, que abre novas possibilidades de participação social frente ao consumo dos bens individuais e coletivos da cidade;

Consórcios Inter-Minicipais e Associações de Municípios, que integram municípios em torno de problemas comuns, estimulando a colocação em prática de racionalidades coletivas através da gestão regional e local participativa, integrando oP.P.M. ao P.P.E. nos aspectos que interessam ao desenvolvimento econômico.

\section{Gestão de Iniciativa Municipal}

$O$ tratamento dos limiares entre o interesse social e o interesse público na cidade de São Paulo vem se impondo como contingência de gerenciamento das forças políticas e econômicas do desenvolvimento que jogam mais criticamente nos grandes centros urbanos. 
O P.P.M. vem assumindo nas últimas gestões de governo, a negociação de interesses com a sociedade, mediante concessões e contrapartidas em investimentos e recursos e a destinação destes para finalidades do interesse público. $O$ poder Executivo negocia receitas públicas com o poder Legislativo. 0 empresariado vem negociando a viabilidade e a rentabilidade de seu investimento. A população vem sendo organizada de modo a pressionar na obtenção de benefícios do P.P.M. Estado e sociedade estão ensaiando e operando em parceria, o jogo da acumulação do capital e da reprodução da força de trabalho.

\section{Operações Interligadas - O.I.}

As Operações Interligadas - O.I. consistem na concessão de benefícios à iniciativa privada, referentes à modificação dos índices Urbanísticos e das características de uso e ocupação do solo, mediante contrapartidas em recursós para aplicação em programas de construção e melhoria habitacional de fins sociais.

A Prefeitura do Município de São Paulo, instituiu as O.I. ainda na gestão Jânio Quadros, através da lei 10.209/86 e decreto 26.913/88.

Constam da exposição de motivos do edital de O.I. as justificativas de incapacidade financeira do P.P.M. para reverter o quadro de desenvolvimento urbano da cidade, principalmente a questão de valorização dos terrenos e especulação imobiliária frente à questão da moradia para a população pobre das grandes cidades como São Paulo. O documento alega, ainda, a omissão do P.P.F no esforço comum de resolução do problema.

As O.I., enquanto instrumentos de gestão, apresentam avanços positivos no sentido da articulação entre P.P e sociedade. A fórmula vem obtendo sucesso compatível com o potencial de rentabilidade do solo da cidade, a ponto de despontar como interesse polêmico da gestão do Partido dos Trabalhadores, na proposta do coeficiente de construção 1.0, adotado na formulação do P.D. da cidade.

Pesa contra as O.I. sua ocorrência desvinculada do P.D., o que leva ao uso pragmático por determinadas ideologias políticas em transição no P.P.M.. Todavia, representa um avanço na instrumentação urbanística que resulta não só em intervenções como na acomodação da carga limitativa e restritiva da legislação urbanística aos fatores de desenvolvimento urbano.

\section{Operações Urbanas - O.U.}

As Operações Urbanas - O.U. são instrumentos de cooperação entre P.P.M. e iniciativa privada, através do qual a administração do município coordena a implantação de infra-estrutura e as formas de ocupação de uma área, conforme o estoque de terra edificável. O setor privado fornece os recursos para as obras a serem realizadas.

Esta proposta, que decorre, por sua vez, da proposta do P.D.M.S.P/91, foi instituída pela lei 11.090/91 - da operação urbana Anhangabaú, que tem por objetivo promover a valorização física, ambiental e patrimonial da área envoltória do vale do Anhangabaú, através do estímulo à realização de investimentos imobiliários privados. Como resultado desse estímulo, pretende-se à obtenção de recursos para execução de obras públicas na área. 
A operação urbana Anhangabaú, por razões ligadas, principalmente, a situação da economia e à forma de sua divulgação, alcançou resultados muito aquém das expectativas.

Do ponto de vista, porém, do instrumento de gestão urbana, as $0 . U$. podem vir a ser estratégicas. Resgatam o projeto de bairro, unidade espacial esquecida dentro da cidade metropolitana. Conduzem a uma ótica de intervenção desenvolvimentista e não só curativa ou restritiva do desenvolvimento urbano, que é a lógica que predomina nos I.U. vigentes.

\section{Siglas Adotadas}

$\begin{array}{ll}\text { I.I.U. } & \text { - Instrumentos de Intervenção Urbanística } \\ \text { I.U. } & \text { - Instrumentos Urbanísticos } \\ \text { P.U. } & \text { - Política Urbana } \\ \text { P.D. } & \text { - Plano Diretor } \\ \text { P.P } & \text { - Poder Público } \\ \text { P.P.F } & \text { - Poder Público Federal } \\ \text { P.P.E. } & \text { - Poder Público Estadual } \\ \text { P.P.M. } & \text { - Poder Público Municipal } \\ \text { C.F } & \text { - Constituição da República Federativa do Brasil } \\ \text { C.E.S.P. - Constituição do Estado de São Paulo } \\ \text { O.I. } \quad \text { - Operações Interligadas } \\ \text { O.U. } \quad \text { - Operações Urbanas }\end{array}$

\section{Bibliografia}

BELUZZO, Luiz G. M., COUTINHO, Renata. Desenvolvimento capitalista no Brasil. São Paulo: Brasiliense, 1983.

CAMARGO, Aspásia. Os riscos do federalismo incompleto. Rio de Janeiro: F.G.V., 1992.

MARTINS, Ives Gandra da Silva. Competência legislativa retirada dos Estados para os municípios pela nova ordem constitucional. R.T-645, jul. 1989.

MUKAI, Toshio. Plano Diretor - extensão à zona rural -impossibilidade-C.F. In: Boletim de Direito Municipal, set. 1991.

PUCHALA, Rosa Maria de F. B. A urbanização do milagre - O caso de São Paulo. 1984. São Paulo: Dissertação (Mestrado) - Faculdade de Arquitetura e Urbanismo, Universidade de São Paulo.

SILVA, José Afonso da. Leis orgânicas municipais. São Paulo: Faculdade de Direito da Universidade de Sāo Paulo, 1990.

ZARATIN, Sérgio, PUCHALA, Rosa Maria de F B. Planos diretores municipais - Registro e sistematizaçāo de experiências piloto. São Paulo: EMPLASA, Documento de Divulgação Interna, 1992.

Plano diretor e planejamento municipal. In: SEMINÁRIO DO PLANO DIRETOR MUNICIPAL. São Paulo: 1989, FAUUSP/FUPAM.

. Prefeitura do Municipio de São Paulo-Proposta do Plano Diretor do Município. São Paulo: Prefeitura do Município de São Paulo: 1991.

Prefeitura do Município de São Paulo. Empresa municipal de urbanização-Operação urbana do centro. Sāo Paulo: PMSP, Documento de Divulgação Interna, 1993. 